\title{
Biomechanical comparison of short-segment posterior fixation including the fractured level and circumferential fixation for unstable burst fractures of the lumbar spine in a calf spine model
}

\author{
Azad Sait, MS, ${ }^{1}$ Nadipi Reddy Prabhav, PhD, ${ }^{2}$ Vijay Sekharappa, MS, ${ }^{1}$ Reshma Rajan, MSc, PhD, ${ }^{3}$ \\ N. Arunai Nambi Raj, PhD, ${ }^{3}$ and Kenny Samuel David, MS ${ }^{1}$ \\ ${ }^{1}$ Spinal Disorders Surgery Unit, Department of Orthopaedics, Christian Medical College, Vellore, Tamil Nadu, India; and ${ }^{2}$ School \\ of Biosciences and Technology and ${ }^{3}$ Division of Photonics and Medical Physics, Vellore Institute of Technology, Vellore, Tamil \\ Nadu, India
}

\begin{abstract}
OBJECTIVE There has been a transition from long- to short-segment instrumentation for unstable burst fractures to preserve motion segments. Circumferential fixation allows a stable short-segment construct, but the associated morbidity and complications are high. Posterior short-segment fixation spanning one level above and below the fractured vertebra has led to clinical failures. Augmentation of this method by including the fractured level in the posterior instrumentation has given promising clinical results. The purpose of this study is to compare the biomechanical stability of shortsegment posterior fixation including the fractured level (SSPI) to circumferential fixation in thoracolumbar burst fractures.

METHODS An unstable burst fracture was created in 10 fresh-frozen bovine thoracolumbar spine specimens, which were grouped into a Group A and a Group B. Group A specimens were instrumented with SSPI and Group B with circumferential fixation. Biomechanical characteristics including range of motion (ROM) and load-displacement curves were recorded for the intact and instrumented specimens using Universal Testing Device and stereophotogrammetry.

RESULTS In Group A, ROM in flexion, extension, lateral flexion, and axial rotation was reduced by $46.9 \%, 52 \%, 49.3 \%$, and $45.5 \%$, respectively, compared with $58.1 \%, 46.5 \%, 66.6 \%$, and $32.6 \%$ in Group B. Stiffness of the construct was increased by $77.8 \%, 59.8 \%, 67.8 \%$, and $258.9 \%$ in flexion, extension, lateral flexion, and axial rotation, respectively, in Group A compared with $80.6 \%, 56.1 \%, 82.6 \%$, and $121.2 \%$ in Group B; no statistical difference between the two groups was observed.
\end{abstract}

CONCLUSIONS SSPI has comparable stiffness to that of circumferential fixation.

http://thejns.org/doi/abs/10.3171/2016.4.SPINE1671

KEY WORDS burst fracture; posterior short-segment fixation; circumferential fixation; biomechanical study; lumbar spine

$\mathrm{B}$ URST fractures commonly occur in young adults due to road traffic accidents or a fall from a height, ${ }^{19,39}$ and they represent $10 \%-20 \%$ of all injuries in the thoracolumbar region. ${ }^{9}$ Because these fractures are commonly encountered in the younger age group, there is a significant economic burden on the family and society owing to loss of work, disability related to neurological deficits, and treatment expenses.
Burst fractures are considered unstable when there is more than a $50 \%$ loss of vertebral body height ${ }^{26}$ or when there is more than $20^{\circ}$ of angulation at the thoracolumbar junction. ${ }^{26,29}$ Instrumented surgical stabilization is currently the treatment of choice for unstable burst fractures. ${ }^{18,32,40}$ Since the advent of pedicle screws, the posterior approach has been increasingly favored in the treatment of these injuries. Long posterior constructs offer greater mechanical

ABBREVIATIONS BMD = bone mineral density; LDC = load displacement curve; $L S C=$ Load Sharing Classification; $N P=$ neutral point; $R O M=$ range of motion; $S S P I=$ short-segment posterior fixation including the fractured level.

SUBMITTED January 13, 2016. ACCEPTED April 18, 2016.

INCLUDE WHEN CITING Published online June 10, 2016; DOI: 10.3171/2016.4.SPINE1671. 
stability, but their placement entails longer surgical exposures and the immobilization of a greater number of motion segments. There has been a transition from long- to short-segment instrumentation in efforts to preserve motion segments. ${ }^{11,16}$ However, posterior short-segment fixation constructs spanning one level above and one below the fractured vertebra can lead to early implant failure and kyphosis in unstable burst fractures., ${ }^{4,27,41}$ Various techniques have been described to augment the stability provided by short posterior pedicle screw constructs. These include percutaneous balloon vertebroplasty, ${ }^{2}$ supplementation with sublaminar hooks, ${ }^{6}$ addition of cross-links, ${ }^{10,22}$ and insertion of a screw into the fractured vertebra. ${ }^{12,14,24}$ Insertion of pedicle screws into the fractured level in addition to fixing one level above and one below has shown promising clinical results, with a lower incidence of implant failure and kyphosis. ${ }^{12,16}$ This is a less morbid and less time-consuming technique and helps in rapid rehabilitation.

Circumferential fixation using combined anterior and posterior approaches aids in direct decompression of the neural canal and reconstructs the unstable anterior and middle column using a stable mechanical device such as Harms cage, which is secured in compression by the posterior instrumentation. It allows for the use of a stable short-segment construct and preserves motion levels, ${ }^{1,26}$ but it is associated with higher morbidity rate and operative complications. ${ }^{19}$

To our knowledge, there are no biomechanical studies directly comparing these two clinically successful fixation techniques. If both fixation techniques provide comparable stability under physiological loads, the one that causes less morbidity and is familiar to most surgeons can be chosen as a viable alternative to the other in treating unstable burst fractures. Our study is aimed at comparing the biomechanical stability achieved by short-segment posterior fixation including the fractured level (SSPI) to circumferential fixation.

\section{Methods}

\section{Study Design: Experimental Comparative Study \\ Specimen Collection and Preparation}

Institutional review board and ethics committee approvals were obtained. Ten spine specimens including the last two thoracic and first three lumbar vertebrae were harvested fresh from dairy calves of 4 to 6 months age. Specimens were obtained from a local slaughterhouse. Plain radiographs were obtained to rule out any gross pathology. Specimens were weighed and a DEXA (dual energy x-ray absorptiometry) scan was obtained to ensure that there is no gross difference among the specimens. Specimens were assigned to one of two groups-A or B (Table 1)-depending on the weight and bone mineral density (BMD). Specimens were labeled, double-packed in polythene bags, and stored in a deep freezer at $-70^{\circ} \mathrm{C}$.

One specimen was tested at a time. Before testing, the specimen was thawed over night at room temperature. The residual soft tissues were removed carefully, preserving the bony and discoligamentous anatomy (Fig. 1A-C). The end vertebrae were trimmed to fit the mounting cup and mounted using dental resin.
TABLE 1. Grouping of the specimens based on weight and BMD

\begin{tabular}{ccc}
\hline Specimen No. & Weight $(\mathrm{g})$ & BMD $\left(\mathrm{g} / \mathrm{cm}^{2}\right)$ \\
\hline A1 & 430 & 0.912 \\
\hline B1 & 410 & 0.927 \\
\hline A2 & 390 & 0.877 \\
\hline B2 & 390 & 0.865 \\
\hline A3 & 450 & 0.768 \\
\hline B3 & 460 & 0.783 \\
\hline A4 & 360 & 0.686 \\
\hline B4 & 350 & 0.651 \\
\hline A5 & 390 & 0.812 \\
\hline B5 & 400 & 0.835 \\
\hline
\end{tabular}

* $A=$ Group A specimen; $B$ = Group B specimen.

\section{Creation of Unstable Burst Fracture}

After the intact spine was biomechanically tested, an unstable burst fracture was created at the L-1 vertebra by drop-weight method. The index vertebra, L-1, was weakened by making drill holes in the upper third in an $\mathrm{H}$ shaped fashion. A weight of $4.5 \mathrm{~kg}$ was dropped along a rail from a height of $1.25 \mathrm{~m}$ on to the upper end of the mounted specimen, which was kept in mild flexion., ${ }^{3,28,33}$ The specimen was then wrapped in saline-soaked gauze and immediately taken for CT scanning. The fracture pattern was studied in detail with the help of 3D reconstructed CT scans (Fig. 2A-C).

\section{Instrumentation}

Once the fracture had been created and the CT scan had been taken, the specimen was immediately instrumented. Group A specimens were instrumented with SSPI (Fig. 3A and B). Group B specimens, after anterior corpectomy, were instrumented with circumferential fixation involving an anterior cage that was held in position under compression using pedicle screws one level above and below the index vertebra, simulating a combined anteriorposterior procedure (Fig. 3C and D). All specimens were instrumented using 5-mm-diameter, 34- to 38-mm-long. monoaxial pedicle screws (Jayon). The corresponding specimens in each group were instrumented using pedicle screws of the same length. Instrumentation was placed in the standard fashion. There was no visible pedicle violation during instrumentation, nor was there a need for screw repositioning. Plain radiographs obtained following instrumentation showed hardware was well positioned.

\section{Biomechanical Testing}

Specimens were tested in flexion-extension, right-left lateral flexion, and axial rotation in clockwise and anticlockwise directions. The intact specimen was tested first. followed by instrumented specimen after creating a burst fracture. The mounted specimen was firmly fixed to the testing fixture on either end using 4 screws drilled through it. An electromagnetic 3D motion tracking system (Polhemus, Inc.) was used to record the orientation of the spine in space. The 6 degree-of-freedom sensors were attached to the vertebra above and the vertebra below the index lev- 

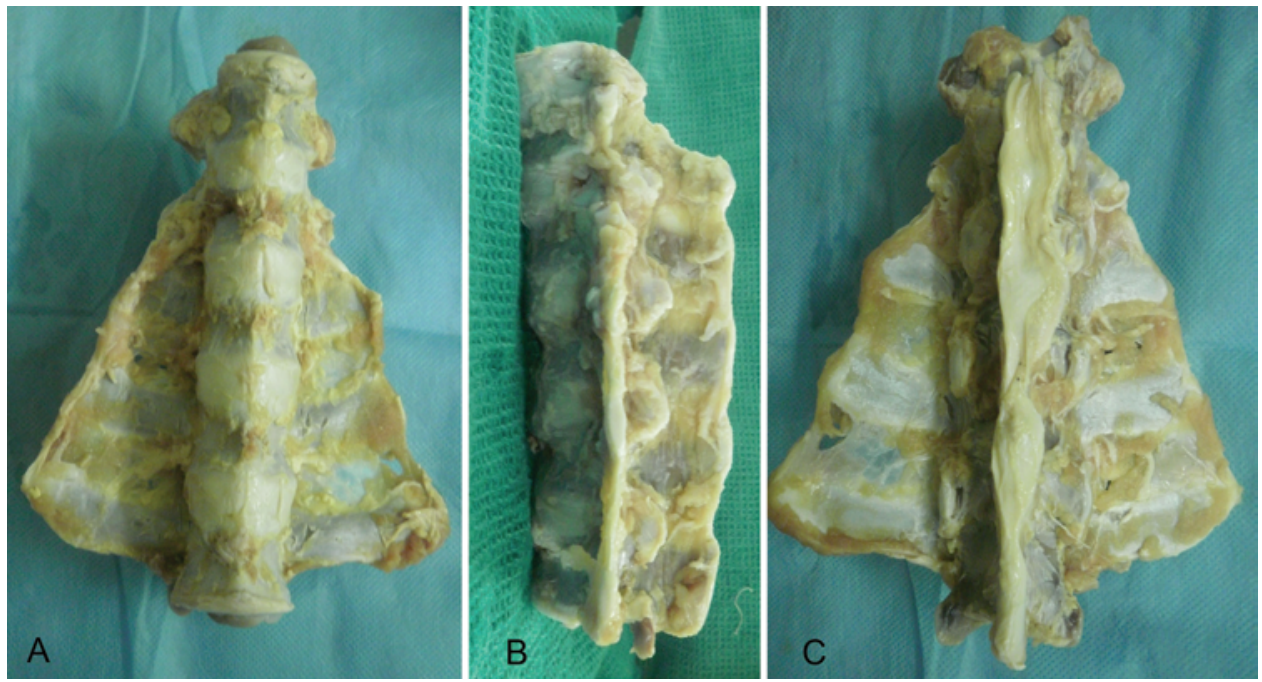

FIG. 1. Anterior (A), lateral (B) and posterior (C) photographs of the prepared specimen showing the retained bony and discoligamentous anatomy after soft-tissue clearance. Figure is available in color online only.

el. Neutral point (NP) coordinates were measured for each test direction before loading. A nondestructive, unidirectional bending moment was applied in each test direction using a Servohydraulic Universal Testing Machine (Tinius, Oslen) having a system of cables and pulleys ${ }^{8}$ (Fig. 4). The test direction was determined by the relative orientation of the specimen to the cables and pulleys. Flexion- extension was tested by orienting the cables sagittally to the specimen, while lateral flexion was tested by orienting the cables coronally. Axial rotation was tested by the horizontal arrangement of the pulleys attached to the upper mounting fixture.

Three preconditioning loading cycles of $200 \mathrm{~N}$ were applied in the test direction at a displacement control
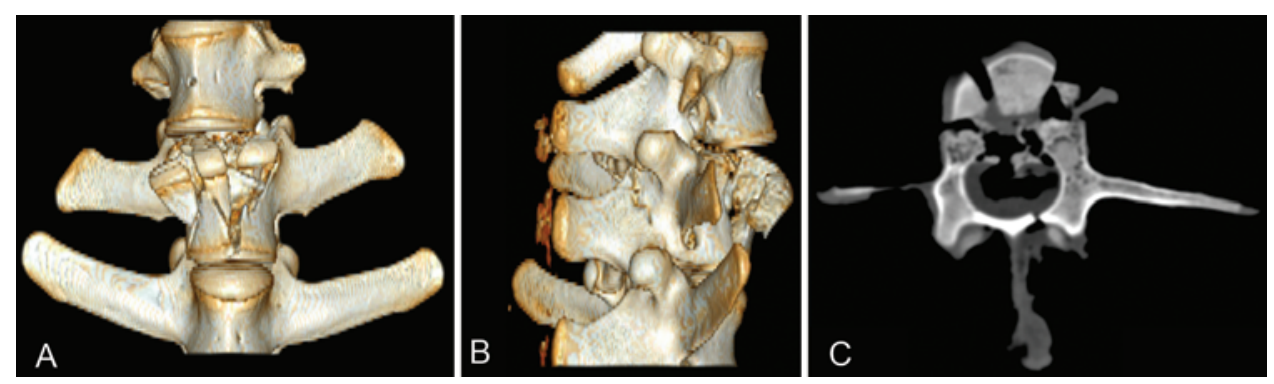

FIG. 2. CT images of a specimen showing the features of an unstable burst fracture: anterior and middle column comminution (A) and vertical laminar fracture (B and $\mathbf{C})$. Figure is available in color online only.
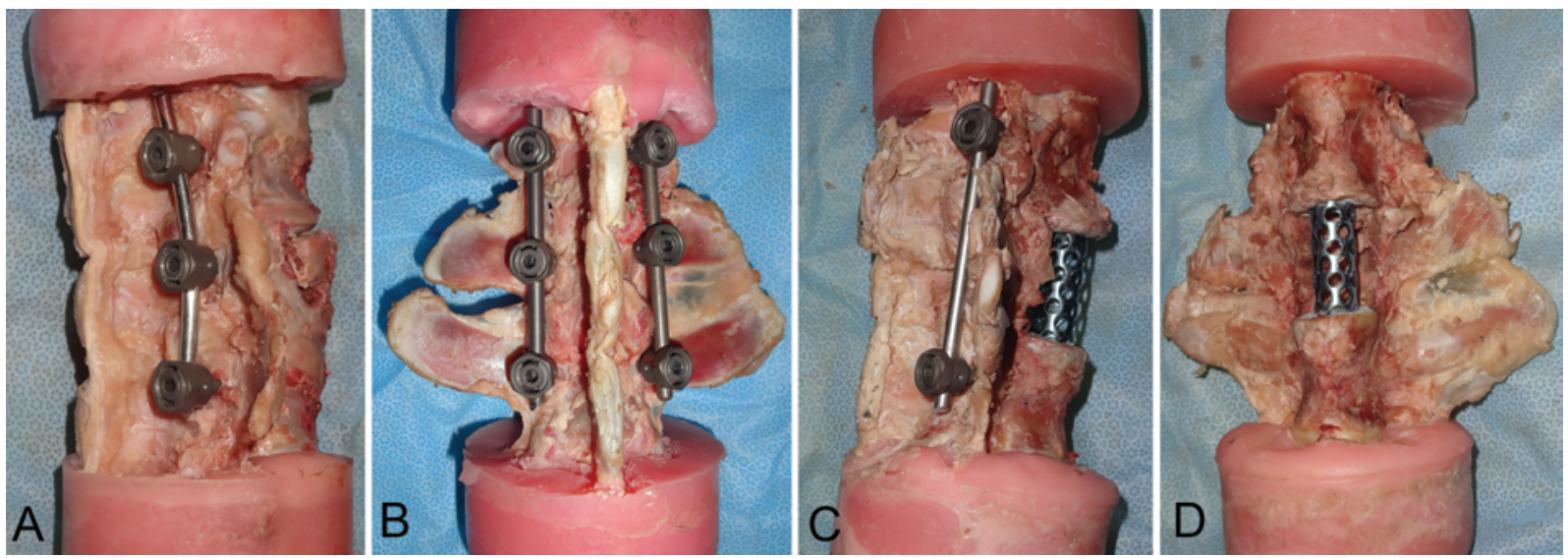

FIG. 3. Instrumented specimens: Group A specimen instrumented with SSPI (A and B) and Group B specimen instrumented with circumferential fixation ( $C$ and $\mathbf{D}$ ). Figure is available in color online only. 


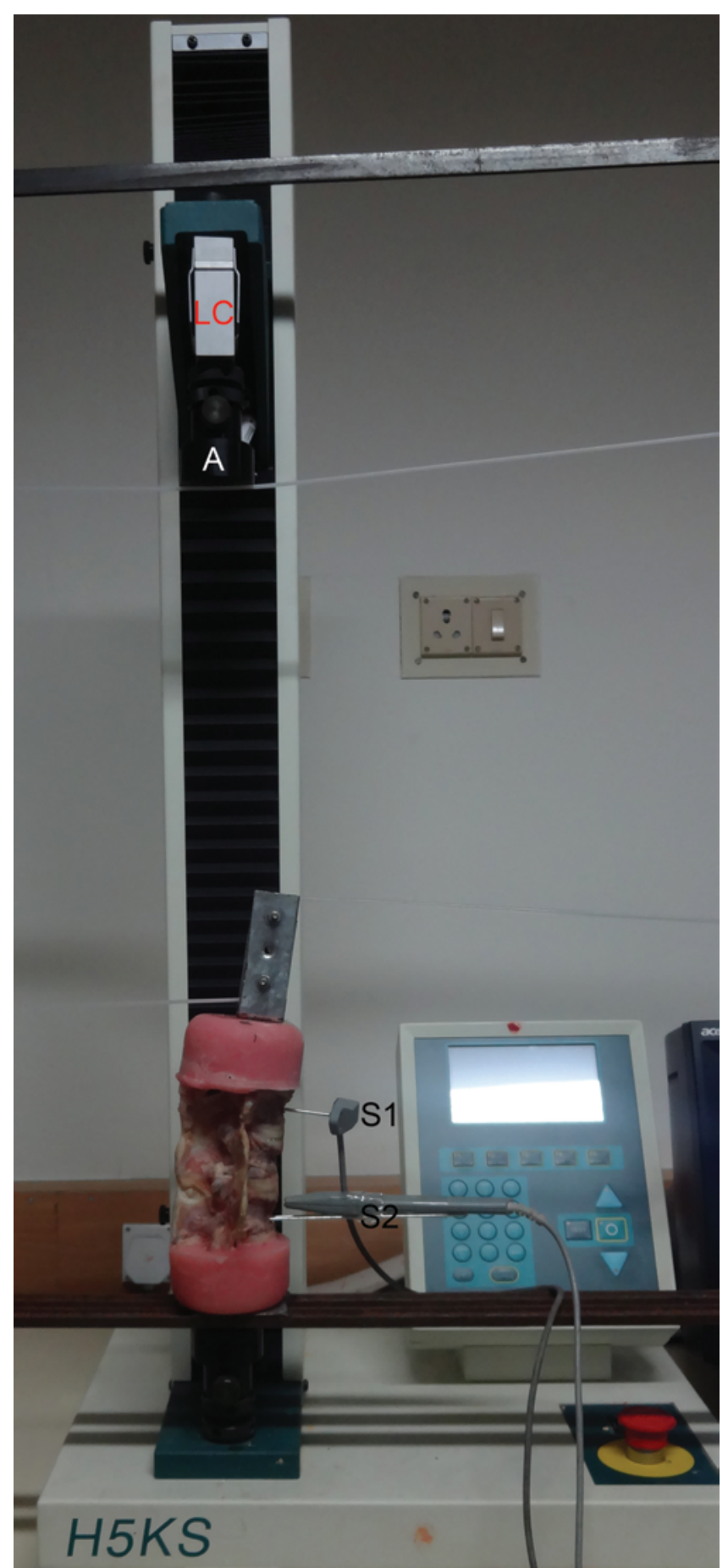

FIG. 4. The test setup for flexion moment. $A=$ actuator; $L C=$ load cell; $S 1$ and $\mathrm{S} 2$ = 6-d.f. motion sensors. Figure is available in color online only.

mode of $5 \mathrm{~mm} / \mathrm{sec}$ to correspond roughly to a bending moment of $7.5 \mathrm{Nm} .{ }^{1}$ Coordinates were recorded after the third preconditioning cycle. The angular change between the NP and the end of the preconditioning cycle was taken as the neutral zone. ${ }^{31}$ The load displacement curve (LDC) obtained from the fourth cycle was used to calculate the stiffness of the construct. The applied load, which was recorded by the load cell placed on the actuator arm of the testing device, was plotted against the displacement of the actuator arm to obtain the LDC. ${ }^{37}$ The stiffness of the construct was calculated from the slope of the elastic zone of LDC and was expressed in newtons/millimeter. A continuous record of the relative motion of the vertebrae in space was obtained for the fourth loading cycle until the peak loading value of $200 \mathrm{~N}$ was reached. The coordinate values were converted into angles using a custom-made software. The range of motion (ROM) was calculated as the angular difference between the NP and the end of the peak loading. ${ }^{13,38}$ The angular difference between the starting point and the end of the fourth loading cycle was taken as the elastic zone of ROM. After the test was completed for each direction, the apparatus was reconfigured for testing in another direction.

\section{Outcome Measures and Statistical Analysis}

The ROM and stiffness of the construct were the primary outcome measures used to determine the stability after placement of the instrumentation..$^{38}$ These two parameters were calculated for each specimen in each test direction, and the values were compared before and after instrumentation for each group using paired t-test. The mean decrease in ROM and the mean increase in the stiffness of the construct after instrumentation were compared between Group A and B for each test direction by using comparison of means.

\section{Results}

Instrumentation significantly reduced ROM and increased construct stiffness for all test directions in both Group A and Group B (Fig. 5). In Group A, ROM in flexion and extension was reduced by $46.9 \%$ and $52 \%$, respectively, compared with $58.1 \%$ and $46.5 \%$, respectively, in Group B. ROM in lateral flexion was reduced by $49.3 \%$ and axial rotation by $45.5 \%$ in Group A, whereas it was reduced by $66.6 \%$ and $32.6 \%$, respectively, in Group B (Fig. $6)$. The ROM decrease in lateral flexion was significantly greater in Group B, while the ROM decrease in axial rotation was significantly greater in Group A ( $p>0.05)$. However, there was no significant difference between the two groups in the decrease in sagittal-plane ROM. Construct stiffness was increased by $77.8 \%$ in flexion, $59.8 \%$ in extension, $67.8 \%$ in lateral flexion, and $258.9 \%$ in axial rotation in Group A and by $80.6 \%, 56.1 \%, 82.6 \%$, and $121.2 \%$ in Group B, respectively (Fig. 7). There was no significant intergroup difference in the increase in construct stiffness after instrumentation.

\section{Discussion}

Treatment of unstable burst fractures has evolved from the use of long- to short-segment fixation in efforts to preserve motion segments. Traditionally, multilevel instrumentation involving 2-3 levels cranially and caudally was used when posterior fusion was performed using hooks and wires, which relied only on posterior fixation points. The advent of pedicle screws that offered transpedicular three-column fixation popularized the short-segment construct, which used the ligamentotaxis to indirectly restore 


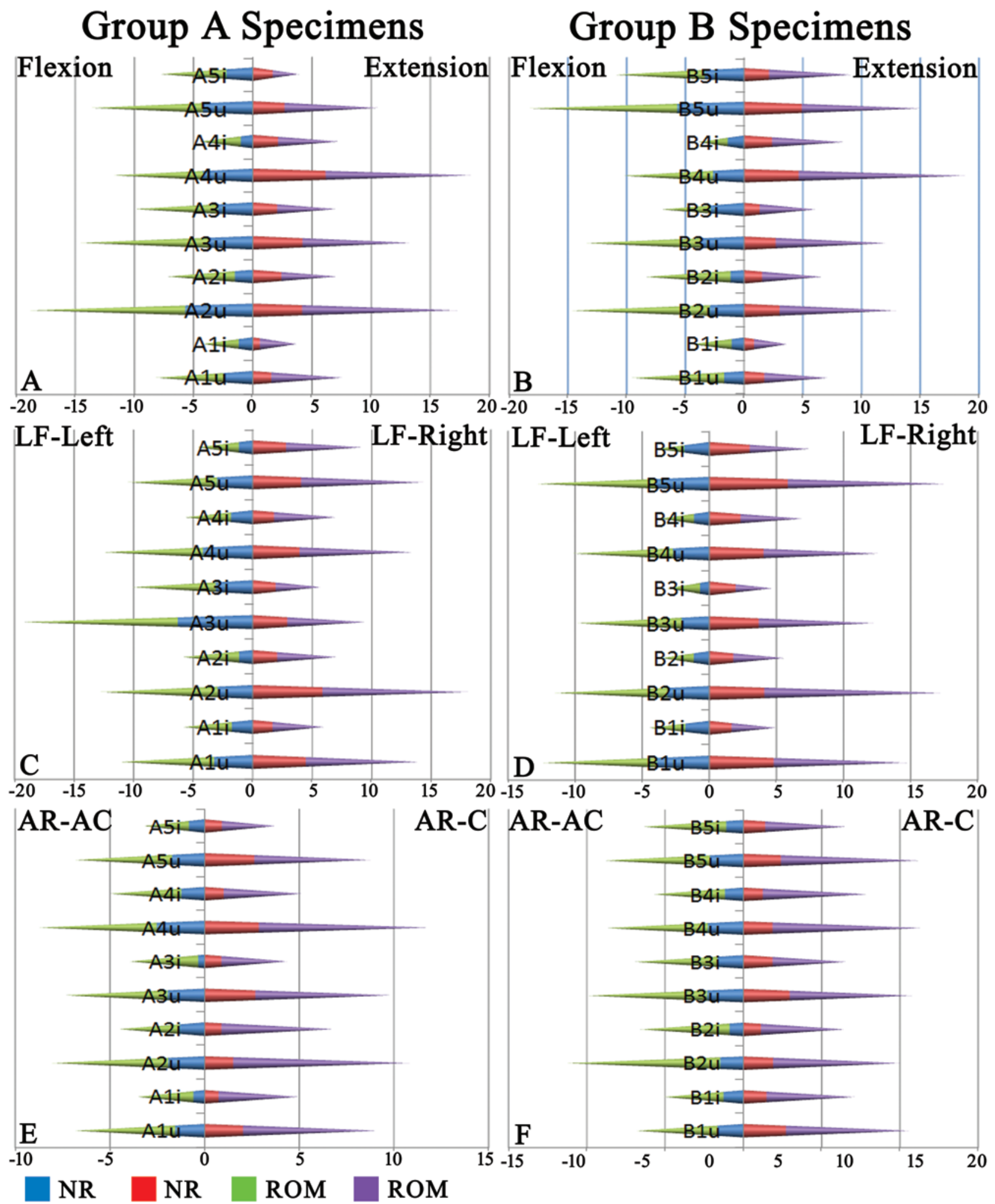

FIG. 5. Graphs depicting ROM for each specimen in Groups $A$ and $B$ before and after instrumentation for coronal (A and $\mathbf{B})$, sagittal (C and D) and axial planes (E and F). A1-A5 and B1-B5 represent specimens in Group A and B. AC = anticlockwise; AR $=$ axial rotation; $C$ = clockwise; $i=$ instrumented; $L F=$ lateral flexion; $N R=$ neutral range; $u=$ uninstrumented. Figure is available in color online only. 


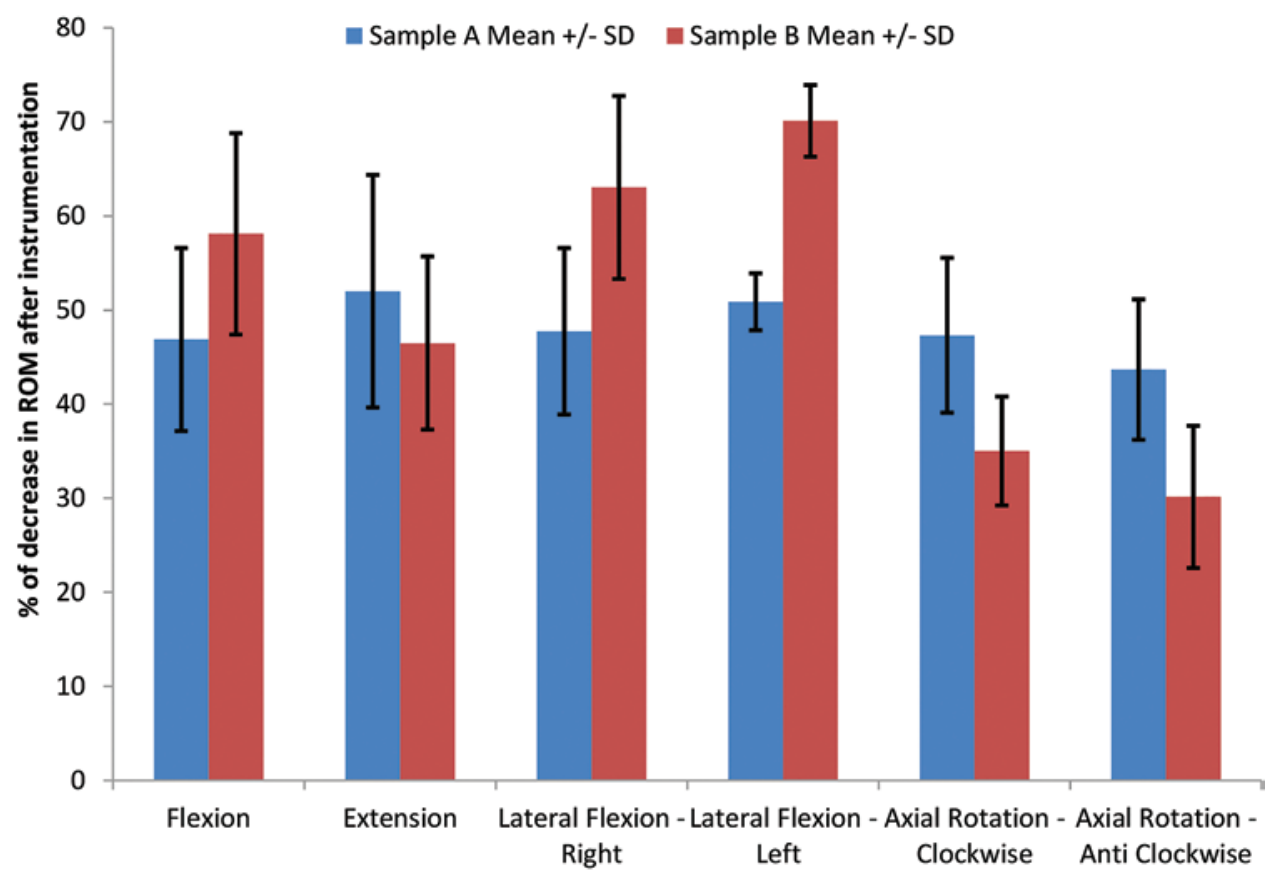

FIG. 6. Graph comparing the percentage of decrease in ROM for each test direction after instrumentation between Group A and Group B. Figure is available in color online only.

the vertebral body height and decompress the neural canal. ${ }^{11}$ Later clinical and biomechanical studies revealed the inadequacy of such a construct, as the short spanning constructs often failed in kyphosis., ${ }^{3,5,12,20,27}$ McCormack et al. pointed out the relevance of anterior column integrity in successful treatment with a short-segment construct ${ }^{25}$ and recommended circumferential fixation in burst fractures that involved severe anterior column disruption.

Circumferential fixation replaces the unstable comminuted anterior column with a stable anterior construct that transmits load across the anterior column in burst fractures with a Load Sharing Classification (LSC) score > 7 proposed by McCormack et al. ${ }^{25}$ This greatly reduces the cantilever bending of the posterior spanning screws and prevents kyphotic collapse. ${ }^{26}$ Circumferential fixation also allows the addition of an anterior fixation device to resist the sagittal-plane forces. Despite the mechanical advantages, its lack of surgeon familiarity, longer operating time, associated blood loss, and complications limit its use, especially in patients with multiple injuries.

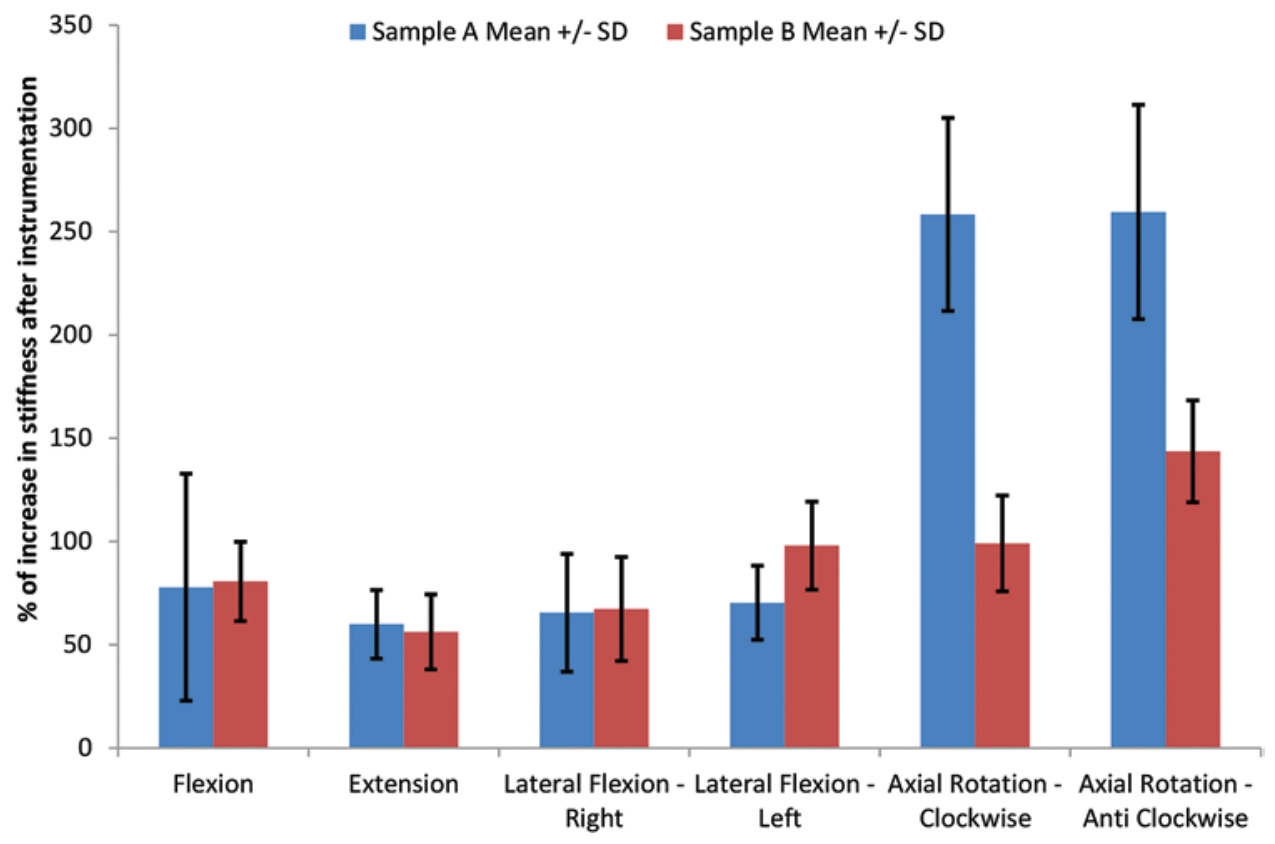

FIG. 7. Graph comparing the percentage of increase in stiffness for each test direction after instrumentation between Group $A$ and Group B. Figure is available in color online only. 
The role of intermediate screws in the long-term maintenance of kyphotic correction in burst fractures with severe anterior column comminution has been well acknowledged in clinical studies. ${ }^{12,16}$ In a recent retrospective review of unstable burst fractures classified as LSC $\geq$ 7 in 32 patients who underwent SSPI, Kanna et al. reported good maintenance of kyphotic correction in a minimum follow-up period of 2 years. The authors questioned the relevance of LSC in predicting implant failure in cases involving intermediate screw fixation. ${ }^{16}$ The biomechanical role of an intermediate screw inserted into the fractured vertebra to augment a short-segment construct is well recognized. ${ }^{3,10,30,35}$ The biomechanical stability conferred by the intermediate screw is based on the fact that most of the stiffness of the construct and the pullout strength of the pedicle screw are derived from the screw's purchase within the pedicle ${ }^{15,21}$ and from the fact that the pedicle is usually intact in a burst fracture of Mager ${ }^{23}$ Grades A.3.1 to A3.3. The addition of another posterior fixation point might also provide an alternative path for load transfer and could theoretically reduce the stress on the individual components of the whole instrumented unit. Intermediate screws may also stiffen the construct by splitting the length of the rod into two half-length parts, thus decreasing motion at the bone-screw interface. ${ }^{3}$

The "intermediate screw" technique is performed via the posterior approach, which is familiar to the majority of spine surgeons. Operating time, blood loss, incidence of intraoperative complications, and duration of hospital stay have all been shown to be significantly lower with this approach. ${ }^{4,19}$ Our results show that both circumferential fixation and short-segment posterior fixation with intermediate screws decrease the ROM significantly and that the construct stiffness does not differ significantly between the two techniques. Considering the relatively superior safety profile of the posterior-only approach, we believe that short-segment posterior fixation in which intermediate screws are placed into the fracture site is a viable alternative to circumferential fixation for stabilizing burst fractures of the thoracolumbar spine.

The use of the calf spine rather than human cadaveric specimens is a potential limitation of our study. However, the calf spine has been shown to best match the anatomy and motion characteristics of the human spine in the thoracolumbar region and is widely used to test pedicle screw systems. ${ }^{7,36}$ Its comparable equivalent BMD, compressive strength, and compressive modulus to that of young human vertebrae make it a good model for young nonosteoporotic human spine ${ }^{34}$ in which burst fractures are commonly encountered. The load-displacement properties and ROM of calf spine specimens have been compared with those of human cadaveric spine specimens in previous biomechanical studies, and calf spine specimens have been proven to be suitable for testing rigid fixation systems using pedicle screws for in vitro flexibility tests. ${ }^{17,37}$ We therefore chose to use calf spines for this comparative study, in part also because they are easily attainable and possess low interspecimen variability.

The use of a fixed pulley system for applying unidirectional bending moments has the potential to create an element of constant deformation termed "impure moment" acting on the spine in all test directions. This necessitates moving the pulleys repeatedly to achieve parallelism of the pulleys and thereby reducing the impure moment acting on the construct. ${ }^{30}$ We avoided readjusting the pulley system repeatedly to minimize the effect on the sensors, which were continuously recording the coordinate points. Moreover, the deformation effect seen was almost identical in all specimens. In the present study we did not evaluate the role of anterior fixation devices in the circumferential construct, although most surgeons performing an anterior approach would prefer to place the hardware anteriorly. Further biomechanical studies are required to compare SSPI to circumferential fixation with additional anterior fixation. Finally, this study compared only the immediate postfixation stability in both groups. The durability of these fixation constructs need to be evaluated using cyclical loading tests. However, we believe the results of this study can be clinically applied in the immediate postoperative rehabilitation of patients who are undergoing short-segment fixation.

\section{Conclusions}

Short-segment fixation with intermediate screws achieves comparable stiffness to that of circumferential short-segment fixation and may be used as an alternative to circumferential fixation in unstable burst fractures of thoracolumbar spine considering the clinical safety of this procedure.

\section{References}

1. Acosta FL Jr, Buckley JM, Xu Z, Lotz JC, Ames CP: Biomechanical comparison of three fixation techniques for unstable thoracolumbar burst fractures. Laboratory investigation. J

Neurosurg Spine 8:341-346, 2008

2. Afzal S, Akbar S, Dhar SA: Short segment pedicle screw instrumentation and augmentation vertebroplasty in lumbar burst fractures: an experience. Eur Spine J 17:336-341, 2008

3. Anekstein Y, Brosh T, Mirovsky Y: Intermediate screws in short segment pedicular fixation for thoracic and lumbar fractures: a biomechanical study. J Spinal Disord Tech 20:72-77, 2007

4. Been HD, Bouma GJ: Comparison of two types of surgery for thoraco-lumbar burst fractures: combined anterior and posterior stabilisation vs. posterior instrumentation only. Acta Neurochir (Wien) 141:349-357, 1999

5. Butt MF, Farooq M, Mir B, Dhar AS, Hussain A, Mumtaz M: Management of unstable thoracolumbar spinal injuries by posterior short segment spinal fixation. Int Orthop 31:259264, 2007

6. Chiba M, McLain RF, Yerby SA, Moseley TA, Smith TS, Benson DR: Short-segment pedicle instrumentation. Biomechanical analysis of supplemental hook fixation. Spine (Phila Pa 1976) 21:288-294, 1996

7. Cotterill PC, Kostuik JP, D’Angelo G, Fernie GR, Maki BE: An anatomical comparison of the human and bovine thoracolumbar spine. J Orthop Res 4:298-303, 1986

8. Crawford NR, Brantley AG, Dickman CA, Koeneman EJ: An apparatus for applying pure nonconstraining moments to spine segments in vitro. Spine (Phila Pa 1976) 20:20972100, 1995

9. Denis F: The three column spine and its significance in the classification of acute thoracolumbar spinal injuries. Spine (Phila Pa 1976) 8:817-831, 1983 
10. Dick JC, Jones MP, Zdeblick TA, Kunz DN, Horton WC: A biomechanical comparison evaluating the use of intermediate screws and cross-linkage in lumbar pedicle fixation. J Spinal Disord 7:402-407, 1994

11. Dick W, Kluger P, Magerl F, Woersdörfer O, Zäch G: A new device for internal fixation of thoracolumbar and lumbar spine fractures: the 'fixateur interne'. Paraplegia 23:225232, 1985

12. Farrokhi MR, Razmkon A, Maghami Z, Nikoo Z: Inclusion of the fracture level in short segment fixation of thoracolumbar fractures. Eur Spine J 19:1651-1656, 2010

13. Goel VK, Panjabi MM, Patwardhan AG, Dooris AP, Serhan $\mathrm{H}$ : Test protocols for evaluation of spinal implants. J Bone Joint Surg Am 88 (Suppl 2):103-109, 2006

14. Guven O, Kocaoglu B, Bezer M, Aydin N, Nalbantoglu U: The use of screw at the fracture level in the treatment of thoracolumbar burst fractures. J Spinal Disord Tech 22:417421, 2009

15. Hirano T, Hasegawa K, Takahashi HE, Uchiyama S, Hara T, Washio T, et al: Structural characteristics of the pedicle and its role in screw stability. Spine (Phila Pa 1976) 22:25042510,1997

16. Kanna RM, Shetty AP, Rajasekaran S: Posterior fixation including the fractured vertebra for severe unstable thoracolumbar fractures. Spine J 15:256-264, 2015

17. Kettler A, Liakos L, Haegele B, Wilke HJ: Are the spines of calf, pig and sheep suitable models for pre-clinical implant tests? Eur Spine J 16:2186-2192, 2007

18. Kifune M, Panjabi MM, Arand M, Liu W: Fracture pattern and instability of thoracolumbar injuries. Eur Spine J 4:98103,1995

19. Korovessis P, Baikousis A, Zacharatos S, Petsinis G, Koureas G, Iliopoulos P: Combined anterior plus posterior stabilization versus posterior short-segment instrumentation and fusion for mid-lumbar (L2-L4) burst fractures. Spine (Phila Pa 1976) 31:859-868, 2006

20. Lazaro BCR, Deniz FE, Brasiliense LBC, Reyes PM, Sawa AGU, Theodore N, et al: Biomechanics of thoracic short versus long fixation after 3-column injury. J Neurosurg Spine 14:226-234, 2011

21. Liljenqvist U, Hackenberg L, Link T, Halm H: Pullout strength of pedicle screws versus pedicle and laminar hooks in the thoracic spine. Acta Orthop Belg 67:157-163, 2001

22. Lynn G, Mukherjee DP, Kruse RN, Sadasivan KK, Albright JA: Mechanical stability of thoracolumbar pedicle screw fixation. The effect of crosslinks. Spine (Phila Pa 1976) 22:1568-1573, 1997

23. Magerl F, Aebi M, Gertzbein SD, Harms J, Nazarian S: A comprehensive classification of thoracic and lumbar injuries. Eur Spine J 3:184-201, 1994

24. Mahar A, Kim C, Wedemeyer M, Mitsunaga L, Odell T, Johnson B, et al: Short-segment fixation of lumbar burst fractures using pedicle fixation at the level of the fracture. Spine (Phila Pa 1976) 32:1503-1507, 2007

25. McCormack T, Karaikovic E, Gaines RW: The load sharing classification of spine fractures. Spine (Phila Pa 1976) 19:1741-1744, 1994

26. McLain RF: The biomechanics of long versus short fixation for thoracolumbar spine fractures. Spine (Phila Pa 1976) 31 (11 Suppl):S70-S79, S104, 2006

27. McLain RF, Sparling E, Benson DR: Early failure of shortsegment pedicle instrumentation for thoracolumbar fractures A preliminary report. J Bone Joint Surg Am 75:162-167, 1993

28. Mermelstein LE, McLain RF, Yerby SA: Reinforcement of thoracolumbar burst fractures with calcium phosphate cement. A biomechanical study. Spine (Phila Pa 1976) 23:664-671, 1998

29. Nagel DA, Koogle TA, Piziali RL, Perkash I: Stability of the upper lumbar spine following progressive disruptions and the application of individual internal and external fixation devices. J Bone Joint Surg Am 63:62-70, 1981

30. Panjabi MM: Hybrid multidirectional test method to evaluate spinal adjacent-level effects. Clin Biomech (Bristol, Avon) 22:257-265, 2007

31. Panjabi MM: The stabilizing system of the spine. Part II. Neutral zone and instability hypothesis. J Spinal Disord 5:390-397, 1992

32. Panjabi MM, Oxland TR, Kifune M, Arand M, Wen L, Chen A: Validity of the three-column theory of thoracolumbar fractures. A biomechanic investigation. Spine (Phila Pa 1976) 20:1122-1127, 1995

33. Sekharappa V, Sait A: Simple and economical method to create thoracolumbar burst fracture in a calf spine model. Asian Spine J 10:6-13, 2016

34. Swartz DE, Wittenberg RH, Shea M, White AA III, Hayes WC: Physical and mechanical properties of calf lumbosacral trabecular bone. J Biomech 24:1059-1068, 1991

35. Wang H, Li C, Liu T, Zhao WD, Zhou Y: Biomechanical efficacy of monoaxial or polyaxial pedicle screw and additional screw insertion at the level of fracture, in lumbar burst fracture: An experimental study. Indian J Orthop 46:395-401, 2012

36. Wilke HJ, Krischak S, Claes L: Biomechanical comparison of calf and human spines. J Orthop Res 14:500-503, 1996

37. Wilke HJ, Krischak ST, Wenger KH, Claes LE: Load-displacement properties of the thoracolumbar calf spine: experimental results and comparison to known human data. Eur Spine J 6:129-137, 1997

38. Wilke HJ, Wenger K, Claes L: Testing criteria for spinal implants: recommendations for the standardization of in vitro stability testing of spinal implants. Eur Spine J 7:148-154, 1998

39. Wood K, Buttermann G, Mehbod A, Garvey T, Jhanjee R, Sechriest V: Operative compared with nonoperative treatment of a thoracolumbar burst fracture without neurological deficit. A prospective, randomized study. J Bone Joint Surg Am 85-A:773-781, 2003 (Erratum in J Bone Joint Surg Am 86-A:1283, 2003)

40. Yazici M, Atilla B, Tepe S, Calisir A: Spinal canal remodeling in burst fractures of the thoracolumbar spine: a computerized tomographic comparison between operative and nonoperative treatment. J Spinal Disord 9:409-413, 1996

41. Yu SW, Fang KF, Tseng IC, Chiu YL, Chen YJ, Chen WJ: Surgical outcomes of short-segment fixation for thoracolumbar fracture dislocation. Chang Gung Med J 25:253-259, 2002

\section{Disclosures}

The authors report no conflict of interest concerning the materials or methods used in this study or the findings specified in this paper.

\section{Author Contributions}

Conception and design: all authors. Acquisition of data: all authors. Analysis and interpretation of data: all authors. Drafting the article: all authors. Critically revising the article: Sait, Prabhav, Sekharappa, David. Statistical analysis: Sait, Prabhav, Rajan, Nambi Raj, David. Administrative/technical/material support: Sait, Prabhav. Study supervision: Sait, Prabhav, Nambi Raj, David.

\section{Correspondence}

Azad Sait, Spinal Disorders Surgery Unit, Department of Orthopaedics, Christian Medical College, Ida Scudder Rd., Vellore, Tamil Nadu 632004, India. email: azadsait83@gmail.com. 